\title{
Concerns of former breast cancer patients about disease recurrence: a validation and prevalence study
}

Citation for published version (APA):

van den Beuken-van Everdingen, M. H. J., Peters, M. L., de Rijke, J. M., Schouten, H. C., van Kleef, M., \& Patijn, J. (2008). Concerns of former breast cancer patients about disease recurrence: a validation and prevalence study. Psycho-Oncology, 17(11), 1137-1145. https://doi.org/10.1002/pon.1340

Document status and date:

Published: 01/01/2008

DOI:

10.1002/pon.1340

Document Version:

Publisher's PDF, also known as Version of record

Document license:

Taverne

Please check the document version of this publication:

- A submitted manuscript is the version of the article upon submission and before peer-review. There can be important differences between the submitted version and the official published version of record.

People interested in the research are advised to contact the author for the final version of the publication, or visit the DOI to the publisher's website.

- The final author version and the galley proof are versions of the publication after peer review.

- The final published version features the final layout of the paper including the volume, issue and page numbers.

Link to publication

\footnotetext{
General rights rights.

- You may freely distribute the URL identifying the publication in the public portal. please follow below link for the End User Agreement:

www.umlib.nl/taverne-license

Take down policy

If you believe that this document breaches copyright please contact us at:

repository@maastrichtuniversity.nl

providing details and we will investigate your claim.
}

Copyright and moral rights for the publications made accessible in the public portal are retained by the authors and/or other copyright owners and it is a condition of accessing publications that users recognise and abide by the legal requirements associated with these

- Users may download and print one copy of any publication from the public portal for the purpose of private study or research.

- You may not further distribute the material or use it for any profit-making activity or commercial gain

If the publication is distributed under the terms of Article $25 \mathrm{fa}$ of the Dutch Copyright Act, indicated by the "Taverne" license above, 


\title{
Concerns of former breast cancer patients about disease recurrence: a validation and prevalence study
}

\author{
Marieke H. J. van den Beuken-van Everdingen'*, Madelon L. Peters², Janneke M. de Rijke', Harry C. Schouten ${ }^{3}$, \\ Maarten van Kleef ${ }^{4}$ and Jacob Patijn' \\ 'Pain Management and Research Center, University Hospital Maastricht, Maastricht, The Netherlands \\ ${ }^{2}$ Department of Clinical Psychological Science, Maastricht University, Maastricht, The Netherlands \\ ${ }^{3}$ Department of Internal Medicine, University Hospital Maastricht, Maastricht, The Netherlands \\ ${ }^{4}$ Department of Anesthesiology, University Hospital Maastricht, Maastricht, The Netherlands
}

* Correspondence to: Pain Management and Research Center, University Hospital Maastricht, P.O. Box 5800, 6202 AZ Maastricht, The Netherlands.

E-mail: MVDB@adcc.azm.nl

Received: 7 September 2007

Revised: 4 December 2007

Accepted: 28 January 2008

\begin{abstract}
Objective: The present study has three aims: first, to evaluate the psychometric properties of the Dutch version of the CARS (CARS-DLV). Second, to measure the prevalence of concerns about disease recurrence in former breast cancer patients and identify potential predictors and third, to establish how fear of recurrence was effecting quality of life.

Methods: A prospective study was carried out on breast cancer patients $(n=136)$ who had undergone curative treatment. Eligible patients completed an extensive questionnaire consisting of the CARS (fear of recurrence), HADS (anxiety and depression), BPI (pain), RAND (quality of life), LOT (optimism) and the PCS (catastrophzing).

Results: This study confirmed the good internal consistency, test-retest stability and construct validity of the CARS (Dutch Language version). Moderate to high levels of fear of disease recurrence were found in $56 \%$ of 136 breast cancer survivors. Worries about health and death were the most prominent. Pain was a strong predictor of overall fear and of fear on the four sub domains of the CARS. The prevalence of fear decreased significantly with age. Education level, living arrangements and time since the last treatment did not predict the prevalence of overall fear. Fear of recurrence was negatively correlated with quality of life.

Conclusion: The CARS-DLV proved to be a valuable instrument to measure women's' concerns about breast cancer recurrence. More than half of former breast cancer patients indicated moderate to severe concerns about disease recurrence. Health and death worries were the most prominent. The levels of worry were independent of the time since diagnosis.

Copyright (C) 2008 John Wiley \& Sons, Ltd.

Keywords: cancer; oncology; fear of recurrence; breast cancer; quality of life
\end{abstract}

\section{Introduction}

To cover all the relevant domains of quality of life (QoL) in breast cancer survivors, current QoL questionnaires should be complemented by aspects such as body image, sexuality and fear of disease recurrence [1]. Breast cancer survivors are faced with many demands of illness, particularly across the physical, psychological, social and spiritual domains [2]. A recent systematic review has shown that long-term survivors of breast cancer were experiencing overall good QOL [3]. In most women, psychological distress (e.g. anxiety and depression) subsided during the first 24 months after diagnosis [4]. However, $30 \%$ of the women were still experiencing psychological distress many years after the completion of treatment [4]. Specific problems often persisted, such as poor body image, decreased sexuality and fear of disease recurrence $[1,5]$. Even 20 years after the initial treatment, there was an increased prevalence of post-traumatic stress disorder (PTSD), which indicated unremitting psychological sequelae long after diagnosis and treatment [6].

Fear of disease recurrence is one of the most prevalent long-term psychological consequences of surviving cancer. In women who survived breast cancer, fear of disease recurrence was reported by 29-97\% [7-14]. The most important long-term sources of distress following breast cancer surgery were shoulder-arm morbidity and fear of cancer recurrence [15]. High levels of fear of recurrence can lead to dysfunctional behavior, including anxious preoccupation and excessive checking [16]. Several cancer-related fears were found to be positively related to depression and anxiety, e.g. worries about disease recurrence or a second primary tumor [17]. The aggregate data gathered from individuals concerning the nature of women's fears about recurrence may help oncology profes- 
sionals to better understand women's coping and adjustment in the presence of such fears and to device more supportive interventions [9].

In the literature, four different instruments are described to measure fear or concerns about disease recurrence: the Fear of Recurrence Index (2 items) [18], the Worry about Cancer Scale (4 items) [19], the Northouse Fear of Recurrence Scale (22 items) [20] and the Concerns About Recurrence Scale (CARS) [8]. The most significant limitation of the first three questionnaires is that they evaluate women's overall fear of tumor recurrence, without identifying which domains the various concerns relate to. In contrast, the CARS [8] is a multidimensional instrument that addresses different domains of women's fear. Thus, the CARS is able to identify the aspects that patients fear most. Women's fears about recurrence are likely to be influenced by their previous experiences with breast cancer, because expectancies regarding the future are shaped by past experiences [21]. Research has documented numerous psychosocial effects of breast cancer, including the emotional difficulties [22], problems associated with sexuality $[23,24]$, body image [23,25], self-concept [26], femininity [27], financial strain [28], disruptions in daily activities [22], barriers to fulfilling roles or setting/reaching goals [28] and/or problems with interpersonal relationships [29]. Because the consequences of breast cancer are so numerous and varied, women's fears about recurrence should be similarly complex.

We recently translated the CARS into Dutch for use in research and clinical work.

This study has three aims: first, to evaluate the psychometric properties of the Dutch version of the CARS (CARS-DLV) in terms of internal consistency, test-retest reliability and construct validity; second, to measure the prevalence of concerns about disease recurrence in former breast cancer patients and identify potential predictors; and third, to establish how fear of recurrence was a effecting QoL.

\section{Methods}

\section{Study sample}

A prospective study was carried out on breast cancer patients $(n=136)$ who had undergone curative treatment. All the patients had participated in an earlier study on the prevalence of pain in cancer patients (all disease stages, $n=1429$ ) [30]. Former breast cancer patients were selected if they had indicated in the earlier study that they were willing to provide information for future research. Eligible candidates were contacted by telephone to verify their willingness to cooperate and to check whether any of the exclusion criteria applied.
Exclusion criteria were recurrent breast cancer or a new malignancy. Demographic data were available from the earlier study. All the participants gave informed consent.

The study was approved by the Medical Ethics Committee of the University Hospital Maastricht, by the local ethics committees of the hospitals and by the group that coordinates studies that involve general practitioners (CEL).

\section{Instruments}

Concerns about recurrence of cancer were measured with the CARS-DLV. The CARS systematically assesses the extent and the nature of women's concerns about breast cancer recurrence [8]. It has two main parts. In the first part, the overall fear of recurrence is assessed with four questions on frequency, potential for upset, consistency and intensity of fear. Scores are given on a 6-point Likert scale that can range from 1 (not at all) to 6 (continuously, terribly). In the second part, the nature of women's concerns about recurrence is assessed with 26 items subdivided into four domains: health worries (11 items), womanhood worries (7 items), role worries (6 items) and death worries (2 items). Scores are given on a 5-point Likert scale: not at all (0), a little (1), moderately (2), a lot (3) and extremely (4). The original CARS was found to be internally consistent (Cronbach's $\alpha=0.89-0.94)$ and there is preliminary evidence of its validity [8].

The CARS was translated into Dutch by two independent translators (M.dR, M.vdB) and translated back into English by two other independent translators, one of whom is a native English speaker (JPC Lawrence). This back-translated English version was approved by Ms Johnson Vickberg who constructed the original version of the CARS [8].

Pain was measured by four questions (pain now and pain over the past week: least, worst and average) derived from the Brief Pain Inventory [31]. Scores could be given on an 11-point Likert scale that ranged from 0 (no pain) to 10 (worst pain ever).

Anxiety was measured by four questions (1, 3, 5, 7) from the Dutch version of the Hospital Anxiety and Depression Scale (HADS) [32]. The HADS was found to make good assessments of symptom severity and caseness of anxiety disorders (Cronbach's $\alpha=0.68-0.93$ ) and depression (Cronbach's $\alpha=0.67-0.90$ ) in somatic, psychiatric and primary care patients, with a sensitivity and specificity of approximately 0.80 [33]. The four questions used in this study showed high correlation $(\mathrm{Sr}=0.91)$ with the total fear scale of the HADS.

QoL was measured with the RAND 36-item Short Form Health Survey 1.0 [34]. The RAND evaluates eight health domains: physical function- 
ing, bodily pain, role limitations due to personal or emotional problems, emotional well being, social functioning, energy/fatigue and general health perceptions. Internal consistency of the different scales varied from 0.71 to 0.92 , whereas retest correlations varied from 0.58 to 0.82 after 2 months [35].

Dispositional optimism was measured with the Life Orientation Test [36]. The LOT is a 12-item questionnaire on generalized positive outcome expectancies (four items worded in a positive direction, four items worded in a negative direction and four filler items).

Scores are given on a 5-point Likert scale that ranges from 0 (strongly disagree) to 4 (strongly agree). The test has shown adequate internal consistency (Cronbach's $\alpha=0.76$ ) and 4-week retest reliability (0.79) [36].

Pain catastrophizing was measured using the Pain Catastrophizing Scale (PCS) [37]. The PCS consists of 13 items that are scored on a scale from 1 (not at all) to 5 (very much so). The Dutch version of the PCS (PCS-DV) showed good internal consistency (Cronbach's $\alpha=0.85-0.91$ ) and there is evidence of the construct validity and the concurrent validity [38].

\section{Procedure}

Each of the participants was sent the questionnaires and an informed consent form to his/her home address. They were asked to return the questionnaire even if they did not wish to participate. The first 50 respondents who returned a completed questionnaire were asked to complete a second questionnaire 2 weeks later that comprised the CARS and a health change score inventory.

\section{Statistics}

A confirmatory factor analysis was performed using Lisrel (version 8.30) [39] to determine the loading of the different items in each domain. The fit was determined by the standardized root mean square residual (SRMR, adequate if $\leq 0.09$ ) [40] and the comparative fit index (CFI, adequate if $\geq 0.95)[40]$.

Internal consistency was estimated using Cronbach's $\alpha$ coefficient [41]. The intraclass correlation coefficient (ICC) was used to determine the testretest reliability of the CARS in the 50 participants who completed the questionnaire twice.

Construct validity was tested by computing correlations between the CARS and the related measures: anxiety (HADS), pain catastrophizing (PCS) and optimism (LOT) [36]. We predicted that the various fear domains would correlate especially with anxiety and to a lesser extent with pain catastrophizing and optimism (negative) [17].
Pain catastrophizing was expected to have the strongest correlation with health worries.

As the scores on several of the questionnaires were not normally distributed, we employed nonparametric Spearman rank correlations.

To examine whether fear of disease recurrence was significantly related with age, education level, living arrangements, pain and number of months since treatment, linear regression analyses were performed using SPSS version 12.0.1. Age, number of months since treatment and pain were entered as continuous variables. Education was coded as a dichotomous variable (the highest education completed: none, junior school or lower vocational training versus secondary school, advanced vocational training or university degree). The variable 'living arrangements' (living alone versus with a partner) was coded dichotomously. Nonparametric Spearman rank correlations were used to investigate the correlation between $\mathrm{QoL}$ and fear of disease recurrence.

To further investigate whether the type of worries varied by time since treatment, we created three subgroups ( $<1$ month, 1-12 months and $>12$ months after treatment) and compared the scores of these subgroups on the different domains of the CARS using ANOVA. The two subgroups with a longer time since treatment were contrasted with the most recently treated group.

\section{Results}

In the group of 174 eligible patients from the prevalence of pain study, 14 could not be reached and 9 had disease progression. A total of 136 out of the remaining 151 patients agreed to participate (response rate $90 \%$ ). The response rate of the first 50 respondents who were asked to complete the second questionnaire for the test-retest was $100 \%$. There were no differences in demographic characteristics between the responders and the nonresponders. The mean age of the participants was 59 years $(\mathrm{SD}=12)$. Most patients $(n=84)$ finished their curative treatment 6 months or less before participation to this study. Only 12 women finished the therapy 4 or more years ago. The demographic features of the women are given in Table 1.

\section{Reliability and validity of the Dutch version of the CARS}

Confirmatory factor analysis revealed adequate loading of all the items in each domain (Table 2). The SRMR was 0.088 , whereas the CFI was 0.956 [41].

Internal consistency (Cronbach's $\alpha$ ) was good in all the domains: overall fear $\alpha=0.94$, health worries $\alpha=0.94$, womanhood worries $\alpha=0.90$, role worries $\alpha=0.88$ and death worries $\alpha=0.90$. 
Table I. Demographic characteristics

\begin{tabular}{|c|c|}
\hline & Responders $n$ (\%) \\
\hline Women & $136(100)$ \\
\hline \multicolumn{2}{|l|}{ Age groups (years) } \\
\hline $20-40$ & $5(4)$ \\
\hline $40-60$ & $77(56)$ \\
\hline $60-80$ & $50(37)$ \\
\hline$\geq 80$ & $4(3)$ \\
\hline \multicolumn{2}{|l|}{ Marital status } \\
\hline Cohabiting & $95(70)$ \\
\hline Widow & $17(12)$ \\
\hline Divorced & II (8) \\
\hline Single & $9(7)$ \\
\hline Unknown & $4(3)$ \\
\hline \multicolumn{2}{|l|}{ Employment status } \\
\hline Working & $28(2 \mathrm{I})$ \\
\hline Housewife & $54(40)$ \\
\hline Old-age pension & $25(18)$ \\
\hline Disability pension & $21(15)$ \\
\hline Sick leave & $6(4)$ \\
\hline Unknown & $2(6)$ \\
\hline \multicolumn{2}{|l|}{ Education } \\
\hline Primary school & $76(56)$ \\
\hline Secondary school & $39(29)$ \\
\hline College/university & $21(15)$ \\
\hline \multicolumn{2}{|l|}{ Living arrangements } \\
\hline At home with partner & $107(79)$ \\
\hline At home alone & $27(20)$ \\
\hline Other & $2(1)$ \\
\hline \multicolumn{2}{|l|}{ Months since treatment } \\
\hline 0 & $42(31)$ \\
\hline $1-6$ & $42(31)$ \\
\hline $7-12$ & $10(8)$ \\
\hline 13-24 & ।I (8) \\
\hline $25-36$ & $9(6)$ \\
\hline $37-48$ & $9(6)$ \\
\hline $49-60$ & $5(4)$ \\
\hline$>60$ & $7(5)$ \\
\hline Missing & I (I) \\
\hline Total & $136(100)$ \\
\hline
\end{tabular}

The mean interval between the first assessment and the second assessment with the CARS was 22 days (range 9-54 days). There was no correlation between the interval and reproducibility. At the time of completing the second list, $94 \%$ of the participants judged their condition to be the same or slightly better or worse than at the first assessment. Only $6 \%$ of the participants called their condition (very) much better. The ICCs of all the domains were adequate: overall fear 0.78 , health worries 0.86 , womanhood worries 0.89 , role worries 0.79 and death worries 0.77 . Construct validity was confirmed by Spearman's correlation tests between the subscales of the CARS and the HADS, PCS and LOT (Table 3). All the correlations proved to be significant at the 0.01 level (two-tailed).

\section{Prevalence of worries and predictors}

Moderate to high overall levels of fear were reported by $56 \%$ of the women (Figure 1).

Health worries (moderate to high (Likert 2-4) levels in $63 \%$ ) and death worries (moderate to high levels in $61 \%$ ) were the most prevalent. Moderate to high levels of role and womanhood worries were reported by $37 \%$ and $29 \%$, respectively (Figure 1).

Pain was a strong predictor of overall fear and of fear on the four sub domains of the CARS (Table 4). The prevalence of fear decreased significantly with age. Education level, living arrangements (at home with a partner or at home alone) and time since the last treatment did not have any predictive value on the prevalence of overall fear (Table 4). Older women were significantly less worried about health, role and death than younger women. Women with high education levels had significantly more health and role worries than women with low education levels (Table 4). Women living alone had a lower level of role worries than women living with partners.

Differences in the type of worries between the three subgroups of time since treatment $(<1$ month, 1-12 months and $>12$ months) were examined by ANOVA. Neither on overall fear nor on any of the subdomains significant differences in worries between the subgroups (Figure 2) were found (overall fear: $F(2,21)=0.12, p=0.89$; health worries: $F(2,21)=0.051, p=0.95$; womanhood worries: $F(2,21)=1.11, p=0.33$; role worries: $F(2,21)=0.08, p=0.92$; death worries: $F(2,21)=$ $0.14, p=0.87)$.

\section{Association between QoL with worries about recurrence}

All the domains of the CARS were negatively associated with all the domains of the RAND (physical functioning, social functioning, role limitations (physical problems), role limitations (emotional problems), mental health, vitality, bodily pain, general health perception) (Table 5).

The highest correlation was found between worries and mental health. Role worries had the most negative effect on QoL.

\section{Discussion}

This study on the Dutch language version (CARSDLV) of the CARS confirmed the good internal consistency, test-retest stability and construct validity found in the original study [8]. In the literature on the four questionnaires constructed to measure fear of recurrence, data on reliability and validity have been published only on the Northouse Fear of recurrence questionnaire [20] and the CARS. Although all the other available questionnaires will yield similar prevalence rates of fear of 
Table 2. Confirmatory factor analysis of the Dutch version of the concerns about recurrence scale

\begin{tabular}{|c|c|c|c|c|c|}
\hline \multirow[b]{2}{*}{ Item (mean score) } & \multicolumn{5}{|c|}{ Factor loading } \\
\hline & $1^{\mathrm{a}}$ & 2 & 3 & 4 & 5 \\
\hline How frequently do you think about the possibility of recurrence of the cancer (item I) & 0.86 & & & & \\
\hline How upset are you by the possibility of recurrence of your cancer (item 2) & 0.89 & & & & \\
\hline How frequently are you concerned about the possibility that the cancer will recur (item 3) & 0.92 & & & & \\
\hline How afraid are you about the recurrence of your cancer (item 4) & 0.92 & & & & \\
\hline Upset me emotionally (item 5) & & 0.79 & & & \\
\hline Will prevent me from planned activities (item 6) & & 0.74 & & & \\
\hline Will threaten my physical health (item 7) & & 0.83 & & & \\
\hline Require chemotherapy (item 9) & & 0.76 & & & \\
\hline Make me feel I don't have control over my life (item II) & & 0.83 & & & \\
\hline Make me feel less of a woman (item 8) & & & 0.80 & & \\
\hline Threaten my identity (how I see myself) (item 12) & & & 0.70 & & \\
\hline Interfere with my sense of sexuality (item 18) & & & 0.74 & & \\
\hline Threaten my spirituality or faith (item 23) & & & 0.62 & & \\
\hline Lead me to feel less feminine (item 25) & & & 0.90 & & \\
\hline Damage my romantic relationships (item 28) & & & 0.68 & & \\
\hline Make me feel badly about how my body looks or feels (item 30) & & & 0.86 & & \\
\hline Hurt my relationships with friends and family (item 10) & & & & 0.56 & \\
\hline Interfere with my physical ability to carry out daily activities (item 13) & & & & 0.82 & \\
\hline Harm my self-confidence (item I5) & & & & 0.71 & \\
\hline Cause financial problems (item 17) & & & & 0.44 & \\
\hline Keep me from fulfilling my responsibilities (in my home or at my job) (item 24) & & & & 0.80 & \\
\hline Keep me from fulfilling important roles (in my home or at my job) (item 29) & & & & 0.84 & \\
\hline Threaten my life (item I4) & & & & & 0.97 \\
\hline Cause me to die (item 27) & & & & & 0.86 \\
\hline
\end{tabular}

${ }^{\mathrm{a}}$ Factor $\mathrm{I}=$ overall fear; factor 2 = health worries, factor $3=$ womanhood worries, factor $4=$ role worries, factor $5=$ death worries.

Table 3. Construct validity of the CARS: Spearman's correlation coefficients with the HADS, PCS and LOT

\begin{tabular}{llll}
\hline & HADS & PCS & LOT \\
\hline Overall worries & $0.629^{*}$ & $0.336^{*}$ & $-0.390^{*}$ \\
Health worries & $0.665^{*}$ & $0.457^{*}$ & $-0.307^{*}$ \\
Womanhood worries & $0.504^{*}$ & $0.386^{*}$ & $-0.309^{*}$ \\
Role worries & $0.670^{*}$ & $0.375^{*}$ & $-0.379^{*}$ \\
Death worries & $0.594^{*}$ & $0.371^{*}$ & $-0.335^{*}$ \\
\hline
\end{tabular}

*Significant at the 0.01 level (two-tailed)

recurrence, the CARS gives extra valuable information about what the women fear most.

Moderate-to-high levels of overall worry were found in $56 \%$ of the women. This is in concordance with earlier studies that reported prevalence rates of moderate-to-severe fear of recurrence in $55 \%$ [8], 49\% (in post-mastectomy patients) and $46 \%$ (after breast conserving therapy) [10]. In a group of elderly patients ( $>70$ years), the prevalence of moderate-to-severe fear was even as high as $85 \%$ [11]. Other studies reported an overall (mild, moderate or severe) prevalence of fear of recurrence that ranged from 31 to $70 \%[7,12-14,17]$. Several authors described fear of recurrence in more general terms: $22 \%$ of the women declared that fear of recurrence was their most distressing problem [15], in many patients, fear of recurrence permeated day-to-day life 1 year post-cancer diagnosis [42]; fear of recurrence [29] was a very commonly shared experience; fear of recurrence was a major concern [43] or frequently expressed [44] or present to a considerable degree [1].

In agreement with the earlier study by Vickberg [8], women predominantly expressed worries about death and health, whereas role worries and womanhood worries seemed to be weaker concerns.

Our data showed a high prevalence of fear of disease recurrence in former breast cancer patients. A few results have also been published on the prevalence of fear of recurrence in patients with other types of cancer, e.g. orofacial: $>80$ and $72 \%$ at 3 and 7 months post-therapy, respectively, [45], gynecological: between 22 and 64\% [46-49], colorectal: between 27 and 33\% [17] and prostate: 39\% [17]. Patients and their partners stated that disease recurrence was their greatest fear after colorectal cancer [50].

In our study, the time elapsed since the last treatment was not associated with the prevalence of fear of disease recurrence. The literature is contradictory about the influence of time on the fear of recurrence. Some studies suggested that as time progressed the fear of recurrence decreased $[12,13,17,51,52]$, whereas most studies found that time made little difference [28,53-56], even more than 20 years after diagnosis. Importantly, time since diagnosis was unrelated to the frequency of the most important trigger factors for fear of recurrence, e.g. hearing that someone else has cancer, new aches or pains, environmental reminders (e.g. sights, sounds and smells associated with 


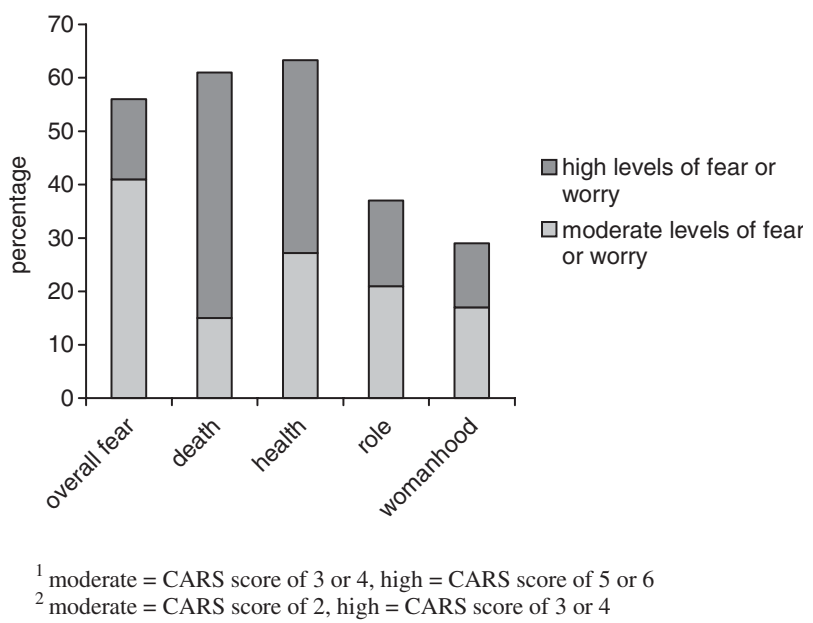

Figure I. Prevalence of moderate to high levels of fear of overall disease recurrence' ${ }^{1}$ and for specific worry domains ${ }^{2}$.

Table 4. Results of the backward linear regression with the domains of the CARS as dependents: predictors of the level of fear of disease recurrence

\begin{tabular}{|c|c|c|}
\hline & Stand. $\beta$ & $p$ \\
\hline \multicolumn{3}{|l|}{$\begin{array}{l}\text { Overall fear } \\
R^{2}=0.127, F=9.288, p<0.001\end{array}$} \\
\hline Pain & 0.286 & $0.00 I^{*}$ \\
\hline Age & -0.211 & $0.012^{*}$ \\
\hline Months since last treatment & -0.035 & 0.679 \\
\hline Living arrangements & -0.072 & 0.422 \\
\hline Education & -0.046 & 0.587 \\
\hline \multirow{2}{*}{\multicolumn{3}{|c|}{$\begin{array}{l}\text { Health worries } \\
R^{2}=0.203, F=10.382, p<0.001\end{array}$}} \\
\hline & & \\
\hline Pain & 0.359 & $<0.00$ I* $^{*}$ \\
\hline Age & -0.204 & $0.014^{*}$ \\
\hline Months since last treatment & 0.019 & 0.822 \\
\hline Living arrangements & -0.005 & 0.956 \\
\hline Education & 0.167 & $0.042^{*}$ \\
\hline \multicolumn{3}{|l|}{ Womanhood worries } \\
\hline \multicolumn{3}{|l|}{$R^{2}=0.107, F=14.815, p<0.001$} \\
\hline Pain & 0.328 & $<0.00$ I* \\
\hline Age & -0.095 & 0.294 \\
\hline Months since last treatment & 0.043 & 0.629 \\
\hline Living arrangements & 0.041 & 0.655 \\
\hline Education & 0.043 & 0.628 \\
\hline \multicolumn{3}{|l|}{$\begin{array}{l}\text { Role worries } \\
R^{2}=0.295, F=14.282, p<0.001\end{array}$} \\
\hline Pain & 0.429 & $<0.00$ I* \\
\hline Age & -0.300 & $<0.00$ I* $^{*}$ \\
\hline Months since last treatment & 0.053 & 0.492 \\
\hline Living arrangements & -0.157 & $0.050^{*}$ \\
\hline Education & 0.190 & $0.013^{*}$ \\
\hline \multicolumn{3}{|l|}{ Death worries } \\
\hline \multicolumn{3}{|l|}{$R^{2}=0.138, F=9,966, P<0.001$} \\
\hline Pain & 0.235 & $0.006^{*}$ \\
\hline Age & -0.293 & $0.00 I^{*}$ \\
\hline Months since last treatment & -0.001 & 0.986 \\
\hline Living arrangements & -0.007 & 0.934 \\
\hline Education & 0.051 & 0.552 \\
\hline
\end{tabular}

*Significant predictors. the period surrounding breast cancer diagnosis and treatment) and information from the media and doctor's appointments [56]. In our study, pain was significantly correlated with all the domains of the CARS and thus appeared to be an important trigger.

Women of more advanced age expressed lower levels of worry in the total, health, role and death domains than the younger women. For womanhood worries, no differences were found between elder and younger women. These findings are in concordance with the existing literature $[8,17,56]$. Explanations could be the generally more aggressive nature of breast cancer in younger women and/or the sense that developing cancer early in life is particularly unexpected or 'off schedule' [8]. Previous studies demonstrated that older women reported significantly fewer triggers than younger women [56].

In our study, women with a higher education level expressed more health and role worries than women with a lower education level. This may be explained by the fact that in earlier studies significantly more triggers were reported by the women with a higher education level [56].

We did not find any relationship between the fear of disease recurrence and living with a partner or alone. Only in the domain of role worries, women living with a partner expressed more worries. An earlier study also reported that living arrangements did not influence the level of fear [20]. However, a strong relationship was found with the presence of significant others, not necessarily living in the same house [20]. In this study, we did not record information on the presence of significant others.

Although the literature showed an overall good QoL in former breast cancer patients, fear of disease recurrence was significantly associated with a poorer QoL: worries about cancer were negatively associated with all the domains of the RAND. Although the differences were small, especially role worries negatively influenced quality of life. More research into different predictive values of the various domains is warranted. Worries about disease recurrence exerted their negative influence on QoL predominantly in the mental health domain of the RAND. Therefore, worries about disease recurrence are mainly a psychological burden. This was also demonstrated by the increased prevalence of PTSD in former breast cancer patients [6] and the positive relation between cancer-related fears and anxiety and depression [17].

In our opinion, targeted interventions are warranted, because fear of recurrence can persist for many years after treatment and it has negative effects on QoL. Unfortunately, very little is known about the effect of psychosocial interventions after the treatment phase [5]. To bridge this gap, a trial recently addressed womens' concerns about disease recurrence 5-9 years after breast cancer treatment 


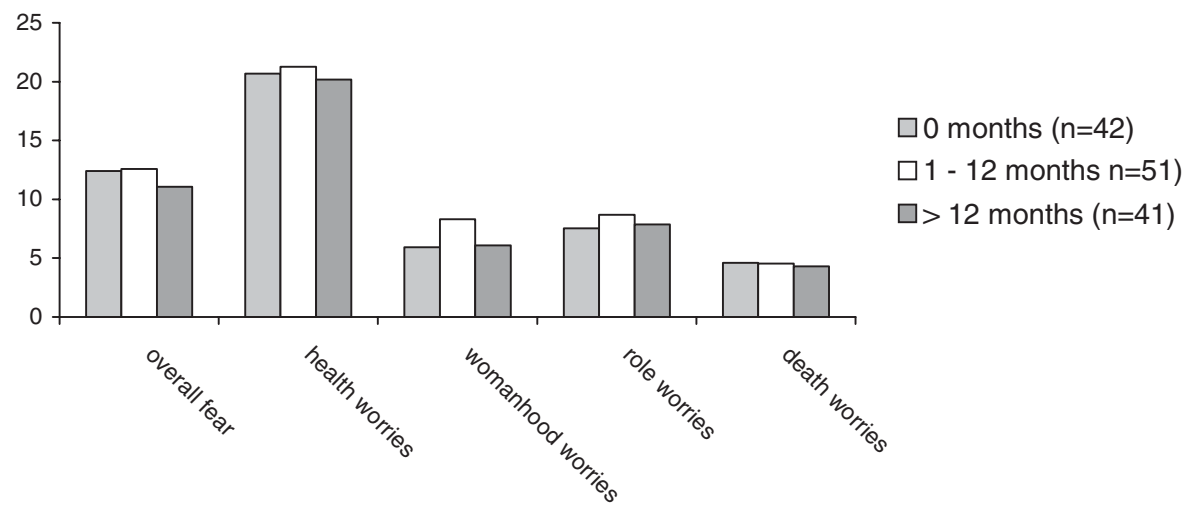

Figure 2. Mean scores of health, womanhood, role, death and overall worries at different points after treatment.

Table 5. Spearman's correlation coefficients ${ }^{\mathrm{a}}$ between fear of disease recurrence and quality of life ${ }^{\mathrm{b}}$

\begin{tabular}{|c|c|c|c|c|c|}
\hline & Overall worries & Death worries & Health worries & Role worries & Womanhood worries \\
\hline \multicolumn{6}{|l|}{ RAND $^{b}$} \\
\hline Physical functioning & -0.215 & -0.236 & -0.359 & -0.423 & -0.369 \\
\hline Social functioning & -0.390 & -0.289 & -0.375 & -0.538 & -0.35 \\
\hline Role limitations (physical problems) & -0.240 & $-0.179^{c}$ & -0.292 & -0.382 & -0.309 \\
\hline Role limitations (emotional problems) & -0.388 & -0.264 & -0.322 & -0.468 & -0.338 \\
\hline Mental health & -0.574 & -0.417 & -0.499 & -0.599 & -0.489 \\
\hline Vitality & -0.376 & -0.289 & -0.381 & -0.528 & -0.41 \\
\hline Pain & -0.272 & $-0.215^{c}$ & -0.358 & -0.391 & -0.315 \\
\hline General health perception & -0.268 & -0.302 & -0.38 & -0.402 & -0.367 \\
\hline
\end{tabular}

${ }^{a}$ All bold correlations were significant on the 0.01 level (two-tailed).

${ }^{b}$ RAND 36-item Health Survey I.0.

${ }^{c} p=0.05$.

[57]. Over a period of 8 months, nurses guided the respondents (by means of four weekly telephone sessions) in the use of audio taped cognitivebehavioral strategies to manage concerns about disease recurrence. At 10 months after the start of the intervention, the women demonstrated enhanced coping skills directed towards their fear of tumor recurrence.

A potential limitation of our study is the relatively small sample size. This could raise questions about the validity of the confirmatory factor analysis. However, the empirical basis for the common rule that a researcher needs at least 10 participants per variable is unclear [58]. More recently, it was indicated that as communalities become lower the importance of sample size increases [59]. With communalities above 0.6 , relatively small samples (less than 100) may be perfectly adequate. According to MacCallum [59, p. 3] our study with communalities around and above 0.6 , variables to a factor ratio of $30: 5$ and a sample size of 136 will achieve a convergence of $100 \%$.

Another limitation is the use of only one fear of recurrence questionnaire. For further validation of the overall fear component the use of other questionnaires is recommended. Future research should also include more potential predictors such as TNM stage and treatment modalities. Finally, in our study most women had had there last treatment less than 1 year ago. For long-term conclu- sions about the worries in the different domains, future research should concentrate on women longer after diagnosis and treatment.

\section{Conclusion}

The CARS-DLV proved to be a valuable instrument to measure womens' concerns about breast cancer recurrence. It not only measured the prevalence of overall fear but also specified worry levels in different domains. More than half of the former breast cancer patients indicated moderateto-severe concerns about disease recurrence. Health and death worries were the most prominent. The levels of worry were independent of the time since diagnosis, which was in agreement with reports in the literature that worries about recurrence tended to compromise QoL for many years.

In response to the increasing number of longterm breast cancer survivors, research should focus on QoL and psychosocial adjustment to the disease.

\section{References}

1. Hartl K, Janni W, Kastner R et al. Impact of medical and demographic factors on long-term quality of life and body image of breast cancer patients. Ann Oncol 2003;14:1064-1071. 
2. Ferrell BR, Grant M, Funk B et al. Quality of life in breast cancer. Part I: physical and social well-being. Cancer Nurs 1997;20:398-408.

3. Mols F, Vingerhoets AJ, Coebergh JW et al. Quality of life among long-term breast cancer survivors: a systematic review. Eur J Cancer 2005;41:2613-2619.

4. Kornblith AB, Ligibel J. Psychosocial and sexual functioning of survivors of breast cancer. Semin Oncol 2003;30:799-813.

5. Stanton AL. Psychosocial concerns and interventions for cancer survivors. J Clin Oncol 2006;24:5132-5137.

6. Kornblith AB, Herndon 2nd JE, Weiss RB et al. Longterm adjustment of survivors of early-stage breast carcinoma, 20 years after adjuvant chemotherapy. Cancer 2003;98:679-689.

7. Verhoeven K, Crombez G, Van Damme S. Angst voor tergkeer van borstkaner na genezing: de rol van somatosensore amlificatie en trekangst. Gedrag en Gezondheid 2005;33:27-32.

8. Vickberg SM. The Concerns About Recurrence Scale (CARS): a systematic measure of women's fears about the possibility of breast cancer recurrence. Ann Behav Med 2003;25:16-24.

9. Johnson Vickberg SM. Fears about breast cancer recurrence. Cancer Pract 2001;9:237-243.

10. Curran D, van Dongen JP, Aaronson NK et al. Quality of life of early-stage breast cancer patients treated with radical mastectomy or breast-conserving procedures: results of EORTC Trial 10801. The European Organization for Research and Treatment of Cancer (EORTC), Breast Cancer Co-operative Group (BCCG). Eur J Cancer 1998;34:307-314.

11. Aaronson NK, Ahmedzai S, Bergman B et al. The European Organization for Research and Treatment of Cancer QLQ-C30: a quality-of-life instrument for use in international clinical trials in oncology. $J$ Natl Cancer Inst 1993;85:365-376.

12. Mast ME. Survivors of breast cancer: illness uncertainty, positive reappraisal, and emotional distress. Oncol Nurs Forum 1998;25:555-562.

13. King MT, Kenny P, Shiell A et al. Quality of life three months and one year after first treatment for early stage breast cancer: influence of treatment and patient characteristics. Qual Life Res 2000;9:789-800.

14. Meyer L, Aspegren K. Long-term psychological sequelae of mastectomy and breast conserving treatment for breast cancer. Acta Oncol 1989;28:13-18.

15. Kuehn T, Klauss W, Darsow $\mathrm{M}$ et al. Long-term morbidity following axillary dissection in breast cancer patients - clinical assessment, significance for life quality and the impact of demographic, oncologic and therapeutic factors. Breast Cancer Res Treat 2000;64:275286.

16. Lee-Jones C, Humphris G, Dixon R et al. Fear of cancer recurrence - a literature review and proposed cognitive formulation to explain exacerbation of recurrence fears. Psycho-Oncology 1997;6:95-105.

17. Deimling GT, Bowman KF, Sterns S et al. Cancerrelated health worries and psychological distress among older adult, long-term cancer survivors. Psycho-Onco$\log y$ 2006;15:306-320.

18. Lasry JC, Margolese RG. Fear of recurrence, breastconserving surgery, and the trade-off hypothesis. Cancer 1992;69:2111-2115.

19. Easterling DV, Leventhal H. Contribution of concrete cognition to emotion: neutral symptoms as elicitors of worry about cancer. J Appl Psychol 1989;74:787-796.

20. Northouse LL. Mastectomy patients and the fear of cancer recurrence. Cancer Nurs 1981;4:213-220.

21. Kirsch I. How Expectancies Shape Experiences. American Psychological Association: Washington, DC, 1999.
22. Parle M, Jones B, Maquire P. Maladaptive coping and affective disorders among cancer patients. Psychol Med 1996;26:735-744.

23. Schover LR, Yetman RJ, Tuason LJ et al. Partial mastectomy and breast reconstruction. A comparison of their effects on psychosocial adjustment, body image, and sexuality. Cancer 1995;75:54-64.

24. Meyerowitz BE, Desmond KA, Rowland JH et al. Sexuality following breast cancer. J Sex Marital Ther 1999;25:237-250.

25. Moyer A. Psychosocial outcomes of breast-conserving surgery versus mastectomy: a meta-analytic review. Health Psychol 1997;16:284-298.

26. Fife BL. The conceptualization of meaning in illness. Soc Sci Med 1994;38:309-316.

27. Kahane DH. The management of the psychosocial impact of breast cancer. Nurse Pract Forum 1993;4: 105-109.

28. Polinsky ML. Functional status of long-term breast cancer survivors: demonstrating chronicity. Health Soc Work 1994;19:165-173.

29. Ferrell BR, Grant MM, Funk B et al. Quality of life in breast cancer survivors as identified by focus groups. Psycho-Oncology 1997;6:13-23.

30. Beuken-van Everdingen van den MHJ, Rijke de JM, Kessels AG et al. High prevalence of pain in patients with cancer in a large population-based study in the Netherlands. Pain 2007;132:312-320.

31. Daut RL, Cleeland CS, Flanery RC. Development of the Wisconsin Brief Pain Questionnaire to assess pain in cancer and other diseases. Pain 1983;17:197-210.

32. Zigmond AS, Snaith RP. The hospital anxiety and depression scale. Acta Psychiatr Scand 1983;67:361-370.

33. Bjelland I, Dahl AA, Haug TT et al. The validity of the Hospital Anxiety and Depression Scale. An updated literature review. J Psychosom Res 2002;52:69-77.

34. Ware Jr JE, Sherbourne CD. The MOS 36-item shortform health survey (SF-36). I. Conceptual framework and item selection. Med Care 1992;30:473-483.

35. Zee KIvd, Sanderman R, Heyink J. De psychometrische kwaliteiten van de MOS 36-item Shor orm Health Survey (sf-36) in een Nederlandse populatie. Tijdschrift voor Sociale Gezondheidszorg 1993;4:183-191.

36. Scheier MF, Carver CS. Optimism, coping, and health: assessment and implications of generalized outcome expectancies. Health Psychol 1985;4:219-247.

37. Sullivan MJL, Bishop SR, Pivik J. The Pain Catastrophizing Scale: development and validation. Psychol Assess 1995;7:524-532.

38. Van Damme S, Crombez G, Bijttebier P et al. A confirmatory factor analysis of the Pain Catastrophizing Scale: invariant factor structure across clinical and nonclinical populations. Pain 2002;96:319-324.

39. Jöreskog KG, Sörbom D. Lisrel 8.54 (ed 8.54). Scientific Software International: Lincolnwood, IL, USA; 2006.

40. Hu L-t, M BP. Cutoff criteria for fit indexes in covariance structure analysis: conventional criteria versus new alternatives. Struct Equation Modeling 1999;6:1-55.

41. Cronbach L. Coefficient alpha and the internal structure of tests. Psychometrika 1951;16:167-188.

42. Maiedema B, Tatemichi S, MacDonald I. Cancer follow-up care in New Brunswick: cancer surveillance, support issues and fear of recurrence. CJRM 2004;9: 101-107.

43. Fredette SL. Breast cancer survivors: concerns and coping. Cancer Nurs 1995;18:35-46.

44. Noguchi M, Kitagawa H, Kinoshita $\mathrm{K}$ et al. Psychologic and cosmetic self-assessments of breast conserving therapy compared with mastectomy and immediate breast reconstruction. J Surg Oncol 1993;54:260-266. 
45. Humphris GM, Rogers S, McNally D et al. Fear of recurrence and possible cases of anxiety and depression in orofacial cancer patients. Int J Oral Maxillofac Surg 2003;32:486-491

46. Leake RL, Gurrin LC, Hammond IG. Quality of life in patients attending a low-risk gynaecological oncology follow-up clinic. Psycho-Oncology 2001;10:428-435.

47. Fitch M, Gray RE, Franssen E. Perspectives on living with ovarian cancer: young women's views. Can Oncol Nurs $J$ 2000;10:101-108.

48. Fitch MI, Gray RE, Franssen E. Perspectives on living with ovarian cancer: older women's views. Oncol Nurs Forum 2001;28:1433-1442.

49. Wenzel LB, Donnelly JP, Fowler JM et al. Resilience, reflection, and residual stress in ovarian cancer survivorship: a gynecologic oncology group study. PsychoOncology 2002;11:142-153.

50. Northouse LL, Schafer JA, Tipton J et al. The concerns of patients and spouses after the diagnosis of colon cancer: a qualitative analysis. $J$ Wound Ostomy Continence Nurs 1999;26:8-17.

51. Utley R. The evolving meaning of cancer for long-term survivors of breast cancer. Oncol Nurs Forum 1999;26:1519-1523.

52. Ellman R, Thomas BA. Is psychological wellbeing impaired in long-term survivors of breast cancer? $J$ Med Screen 1995;2:5-9.
53. Glynne-Jones R, Chait I, Thomas SF. When and how to discharge cancer survivors in long term remission from follow-up: the effectiveness of a contract. Clin Oncol ( $R$ Coll Radiol) 1997;9:25-29.

54. Thomas SF, Glynne-Jones R, Chait I et al. Anxiety in long-term cancer survivors influences the acceptability of planned discharge from follow-up. Psycho-Oncology 1997;6:190-196.

55. Mehta SS, Lubeck DP, Pasta DJ et al. Fear of cancer recurrence in patients undergoing definitive treatment for prostate cancer: results from CaPSURE. J Urol 2003;170:1931-1933.

56. Gil KM, Mishel MH, Belyea $\mathrm{M}$ et al. Triggers of uncertainty about recurrence and long-term treatment side effects in older African American and Caucasian breast cancer survivors. Oncol Nurs Forum 2004;31: 633-639.

57. Mishel MH, Germino BB, Gil KM et al. Benefits from an uncertainty management intervention for African-American and Caucasian older longterm breast cancer survivors. Psycho-Oncology 2005;14: 962-978.

58. Field A. Discovering Statistics Using SPSS (2nd edn). Sage Publications Ltd: London, 2005.

59. MacCallum RC, Widaman KF, Zhang S et al. Sample size in factor analysis. Psychol Meth 1999; 4:84-99. 